\title{
An Android based Employee Tracking System
}

\author{
Etuk Enefiok A. \\ Department of Computer Sciences, \\ Michael Okpara University of Agriculture, \\ Umudike, Abia State, Nigeria.
}

\author{
Onwuachu Uzochukwu C. \\ Department of Computer Sciences, \\ Imo State University, Owerri, Nigeria
}

\begin{abstract}
In this paper, an employee tracking system based on Android operating system was developed. All the activities of the Employee will be monitored using this system. Scheduling information and time off requests are often considered part of personnel tracking; as this information will enable managers know when employees are expected to actually be in the office or other work areas. This system is really very helpful for the managers to monitor their employees through mobile phones. It was implemented using JAVA programming language, and the result was stored in SQLite database. An object-Oriented Analysis and design (OOAD) approach was adopted which consist of a well-planned iterative steps. Data was collected using document analysis and field Methods and the application of relevant analytical methods like bar-charts were used to interpret the facts collected. The developed system was able to increased productivity, reduction of cost, instant access to employee attendance record.
\end{abstract}

\section{Keywords}

Android Operating System, Tracking system, Employee, JAVA programming and SQLite database

\section{INTRODUCTION}

In a government owned enterprise, the number of employees needed to perform certain functions could run into hundreds if not thousands. Managing and keeping track of these number using traditional methods could prove cumbersome and problematic. The need for an employee tracking information system to assist in the management, monitoring, searching, tracking, updating of the employees records becomes paramount. For instance, some corporate organizations have over 1000 employees. From the process of recruitment up to the employment phase, several data are collected from these employees. The personnel department stores these data manually. Searching for a particular employee record could take hours to find which is not productive in today's fast paced and technologically driven enterprises. This is a simple scenario which currently affects employee tracking system within some corporate organization. Another case scenario could be in keeping track of an employee's current department or departments. It is well known that an employee can serve in more than one department or be moved from one department to another. Keeping track of these transitions could become tedious if no proper system is in place. In this paper, an employee tracking system based on Android operating system was developed. All the activities of the Employee will be monitored using this system. Scheduling information and time off requests are often considered part of personnel tracking; as this information will enable managers know when employees are expected to actually be in the office or other work areas. This system is really very helpful for the managers to monitor their employees through mobile phones. The developed system was able to increased productivity, reduction of cost, instant access to employee attendance record.

\section{LITERATURE REVIEW}

Sonal et al (2016), worked on Employee Tracking and Monitoring System Using Android. In their study the provided different security profile on same smartphone. They used dynamic database utility which retrieves data or information from centralized database. They provided separate mode to employee when he enters company premises. Through smart phones all information about the employee phone like their SMS history, Incoming calls, Outgoing calls, Employee Locations, Data usage, Web browser history, and Unauthorized Call History details are tracked. The necessary condition is that Employees should have the Android phone whereas Manager Activities are also monitored. [1]

Aparna, (2013), worked on Smartphone Monitoring System, The System is a software that allows supervisors to monitor their employee's office cell phone. All incoming call details, outgoing call details, text details, emails and multimedia messages can be seen and interrupted by the managers, who can also monitor where their employees are, access a history of where they have been and set up alerts if their employees are going outside of the approved geographical zones, are receiving texts from unapproved numbers or calls from banned persons. The system helps managers to monitor their employees through mobile phones. It enables organizations can avoid the unnecessary involvement by the employees by monitoring their mobile phone usage and also by tracking their current location.[3]

Priti et al (2015), worked on monitoring employee's smartphone using android application. Thier system uses Android based mobile phones for the software to be run. The mobile device in the hand of the Employee should be an Android based device and the Managers may have any kind of mobile device, since the manager is going to receive alerts from the Employee in SMS format only. For convenience, the alerts are also stored in the centralized server like the details of incoming call, text and multimedia messages and the timely location update of their Employee and their attendance. Manager may later login into the centralized server and view the details of their Employee's mobile usage. This system is helpful for the Managers to monitor their Employee through mobile phones. [2]

Shermin et al (2015), worked on a Smart, Location Based Time and Attendance Tracking System Using Android Application. They proposed a smart location based time and attendance tracking system which is implemented on android mobile application on smartphone reducing the need of additional biometric scanner device. The location of an organization has a specific location, which can be determine by the GPS. Each employee's location can be determined by the GPS using smartphone. [4] 
Nirmal, et al, (2016), worked on Employee Surveillance System Using Android Smart Phone, Their system integrates Employee monitoring and GPS location Tracking System using Android phone. All the activities of the Employee will be monitored using this system. The system works on $3 \mathrm{G}$ communication between the terminal ends. All the activities of an employee on his cell phone and computer, like data usage, all incoming and outgoing calls, web browsing and secured document modification and illegal transfer of company's informative details like blue print, stocks, projects etc. will be set under surveillance. Not only this, the global geographic position of the employee will be traced using GPS. Therefore the organization will be set to surveillance that will restrict the unwanted usage of its resources by the employees during working hours. The system was beneficial for the progress of the organization and will allow the Manager to check the dedication of his employees towards work.[5]

Ashwini et al (2015), worked on Employee Monitoring System Using Android Smartphone. In their study all activities such as incoming, outgoing, missed call, SMS history, web history, data usage, unauthorized call list/web site list are stored on centralized database. Manager can see that history by logging into centralized server. Manager can also trace out employee's current location (through GPS).Employee are going outside of company premises then manager get alert message in SMS format. They analyzed the employee behavior by using numbers of unapproved calls and exceeding data usage (good/bad/average/loyal).The device which is given to employee should be android based device. Manager does not need android device. It may be any device. This system is very helpful for the manager to find out the activities which are done by employee.[6]

Kalyani et al (2015), work on employee monitoring system using android smart phone. In their study paper, they discuss about the design and Implementing admin application, employee application and Centralized server for monitored company employee's using android technology. The system provides dynamic database utility which retrieves data or information from centralized database. The android application in smart phone contains all information about the employee phone uses like their all Employee SMS history, Employee call Logs, Employee Locations, Data uses, Web browser history, and unauthorized data uses details. All communication between the Employee phone and the admin is done through $3 \mathrm{G}$ network technology. This application is user-friendly. The system improves accuracy in managing employees of the company by saving time, reducing manager efforts; avoid the unnecessary use of company phones which are provided to the Employee for their office use only. [7]

Shoewu, et al (2015) worked on Design and Implementation of An Employee Monitoring System In Lasu Epe Campus, Lagos State University, The employee monitoring system is an android application used to monitor the call logs, sent and receive messages and the GPS location of an employee. The application is implemented using Java script, the application interface was designed with $\mathrm{Xml}$ and $\mathrm{Php}$ for the automatic mailing system. The organisations success depends on employees' performance; poor performance is detrimental to the company's success. It is necessary for an employer to keep track of his employees' at all times to ensure the quality of service from the employees' and maximum output from them. This paper deals with the design and development of an employee monitoring system using Android which will be accessed from the company's email account.[8]

Avinaash et al (2015), worked on Mobile Attendance Management and Employee Registration. Staff attendance management and employee registration is a mobile application which can be used by the staffs to login their attendance through mobile phone and track other staffs location through mobile phone. Manual registration in biometric systems and entering in the attendance catalogues in different physical locations is the current system used in all the colleges. The staff will get updates regarding their attendance regularly from the admin as they login and log out so that they can keep a track on their attendance by using this application.[9]

Nitin et al (2015), worked on Mobile Activity Monitoring System Using Android Spy, Their system was implemented for tracking the daily activity of the users with their android mobiles. The information such as missed call, incoming call, outgoing call, call duration, incoming SMS, outgoing SMS along with its date and time will be tracked and updated to the server this server will be monitored by the administrator. This information can be maintained for security purpose of the organization such as leaking the confidential data and maintaining policies of organization.[10]

\section{MATERIAL AND METHOD}

The program uses Android based cell phones for running the implemented software. In this system we can use different modules, and main two apps are employee app and server app. Employee time tracking phone uses data will be stored in centralized server. Mobile device which is on the Head of Department's table should be an Android device and the administrative manager can get the alert through

text messages only. For detailed data it can be stored in the centralized server like the details of incoming call, text and multimedia messages and the timely location update of their Employee. Managers may later login into the centralized server and view the details of their employee's rate of attendance. The classes in the application can be broadly divided into those for UI, background services, data-structure and utilities Design of the new system is demonstrated using CASE diagram as shown in figure 1 


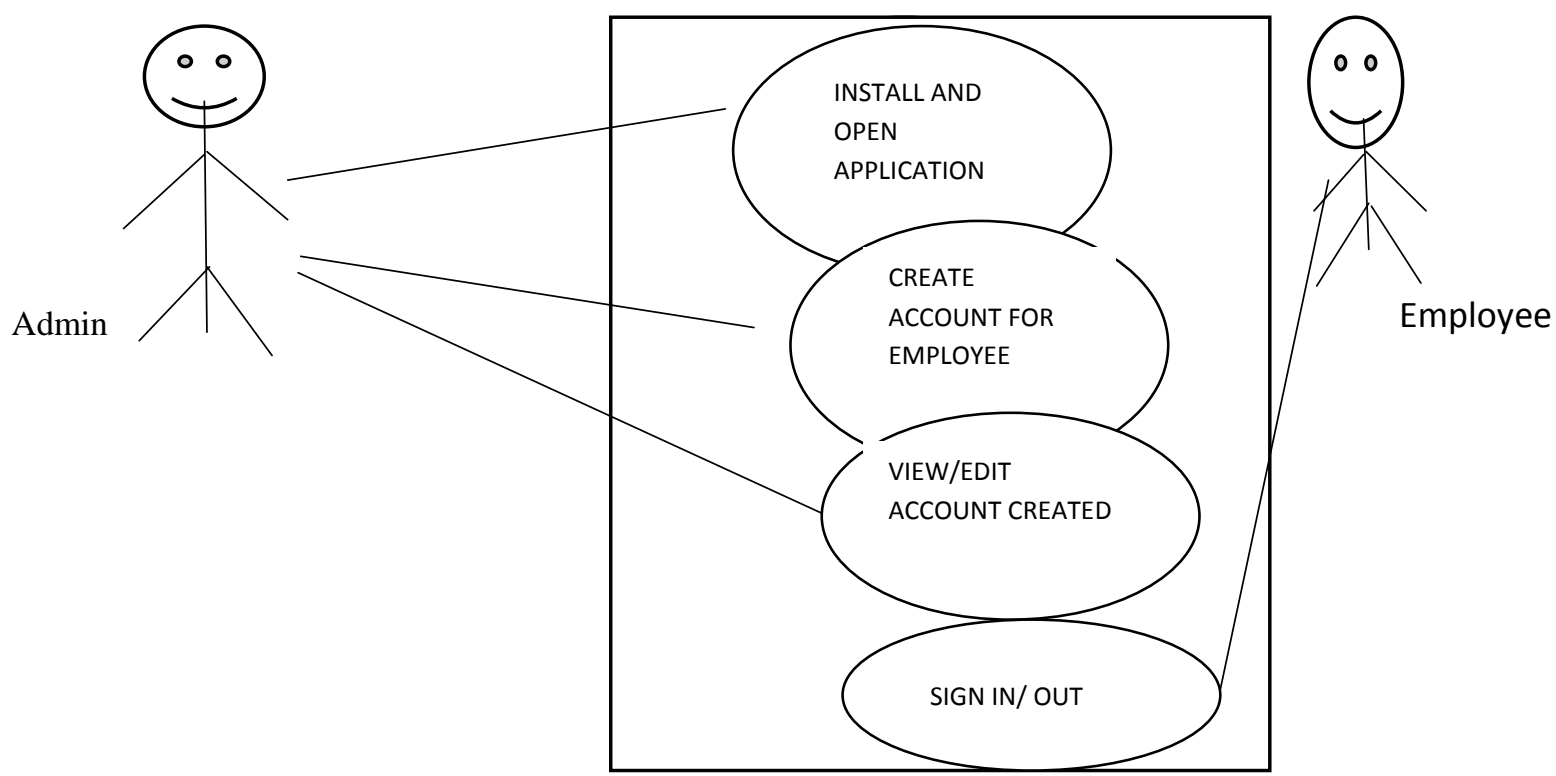

Figure 2: The Case Diagram of the proposed system

figure 2 shows the flow chart of the proposed system, from form the flow chart the application have to be installed in an android phone. From the chart it can be seen that the application was designed for the employee and the employer, the employer is the sole administrator of the application. The administrator uses it to monitor the employee sign in and sign out. 


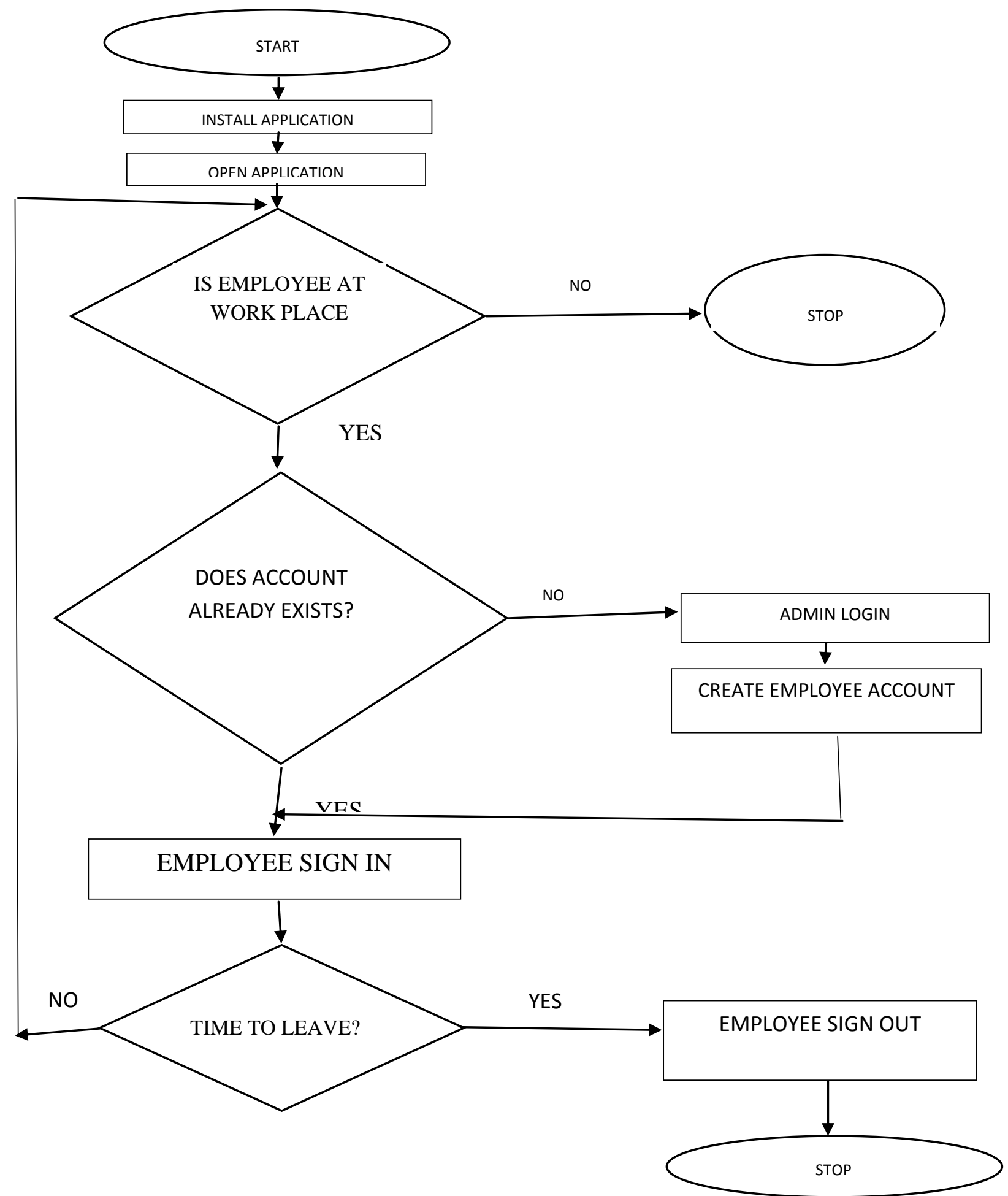

Figure 2. The System Flow Chart of the Android Employee Tracking

\section{RESULT DISCUSSION}

The inputs are to be made by both the database administrator and the employee. On the employee side, he is made to create login and create new employee account, view the account with details on when the employee signed in and out after the days' work. The employee's input is filling of his data as required when creating new account, signing in and out. The password of both the employee and the administrator should be kept confidential to avoid threats. After the admin has logged in, a new employee account can be created by clicking on "Add Employee" button. Figure 3 shows the admin control panel 


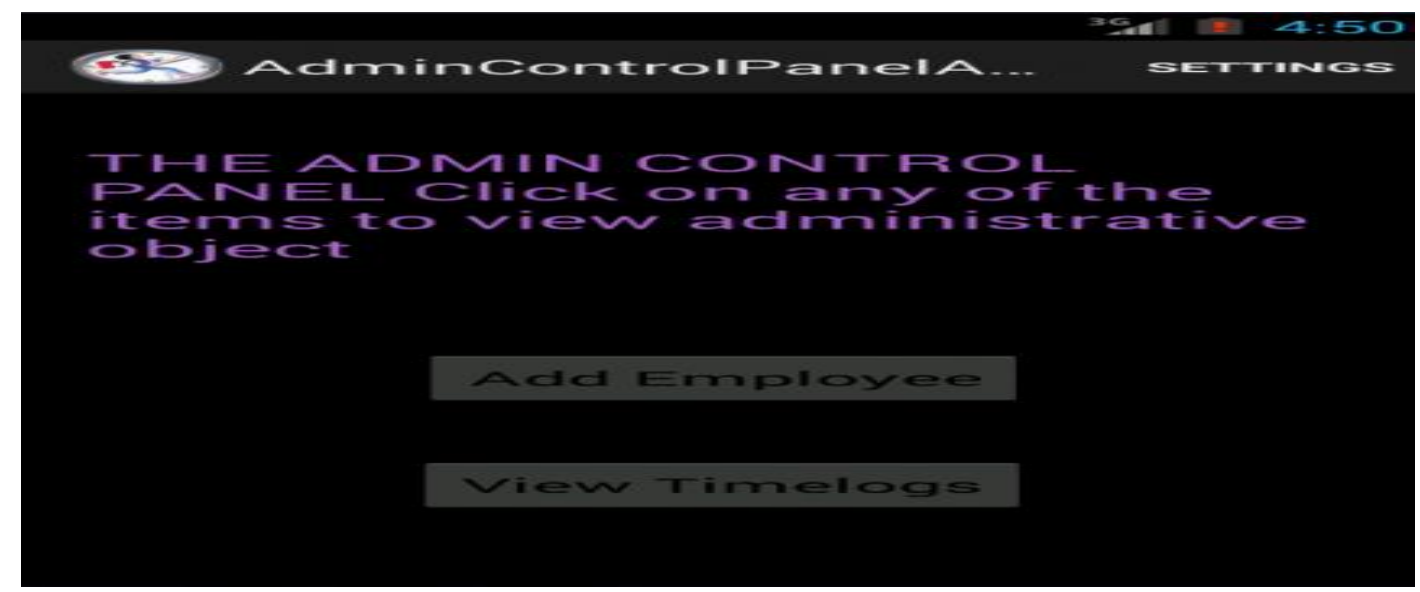

Figure 3: The Admin Control Panel

Figure 4. shows the employee account creation activities. The employee is meant to fill the form shown in figure 4 before an account will be created. The detail of the form includes the employee's full name, the office position, the email address, the password and the phone number.

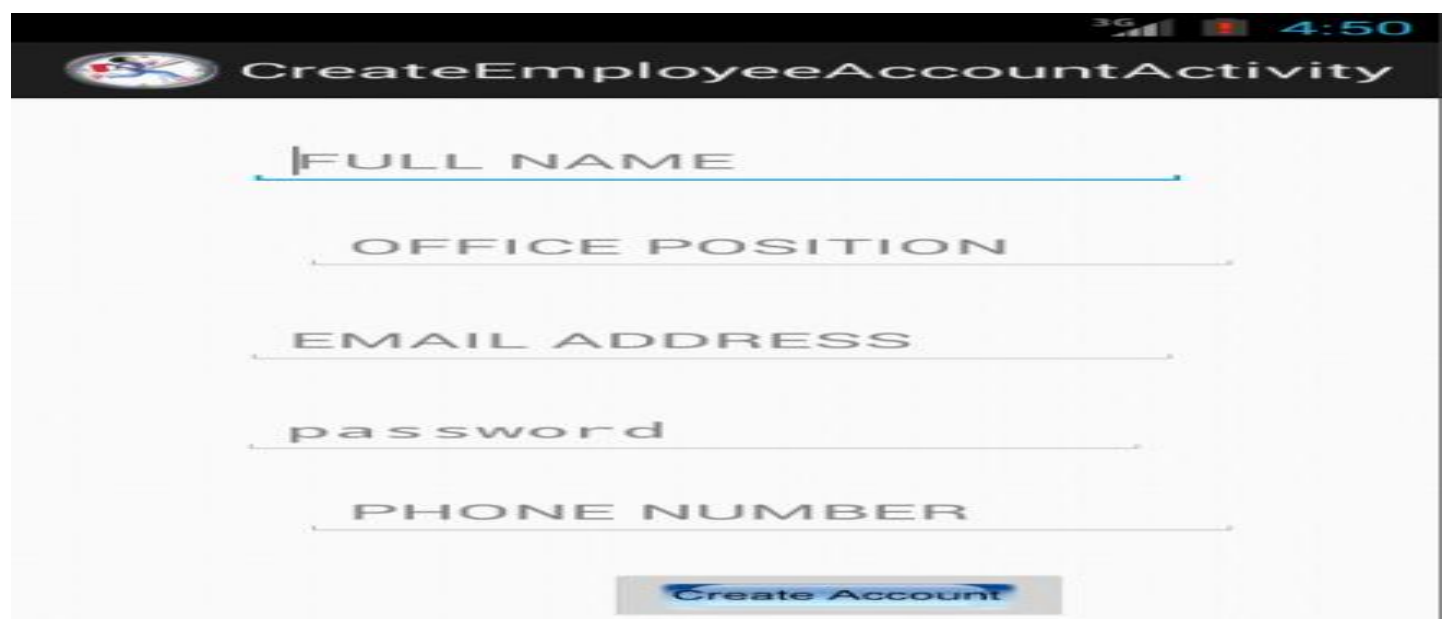

Figure 4: The Employee Account Creation Panel

At successful account creation, the employee can then sign in and out whenever he comes to work and leaves from work using his email and password. The interfaces for sign in and out are shown figure 5 .

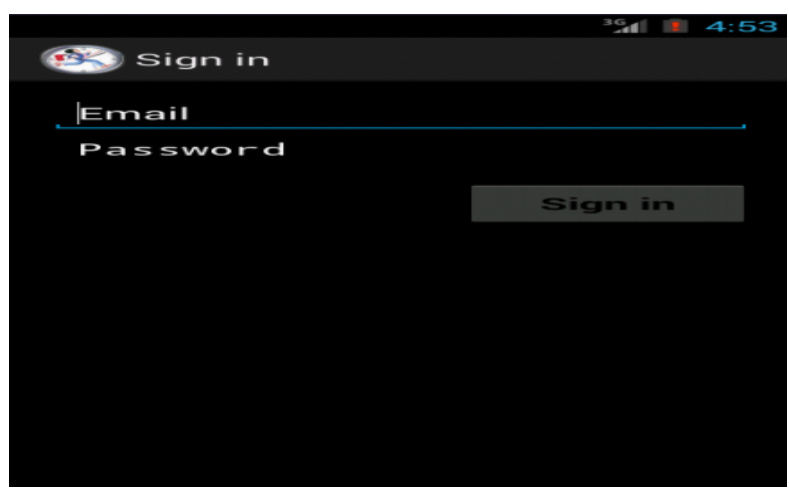

\section{Sign out}

Email

password

Figure 5:Sign in and out interface

For the newly employed staff that just created an account, the database administrator can view the account created as shown in Figure 6. 


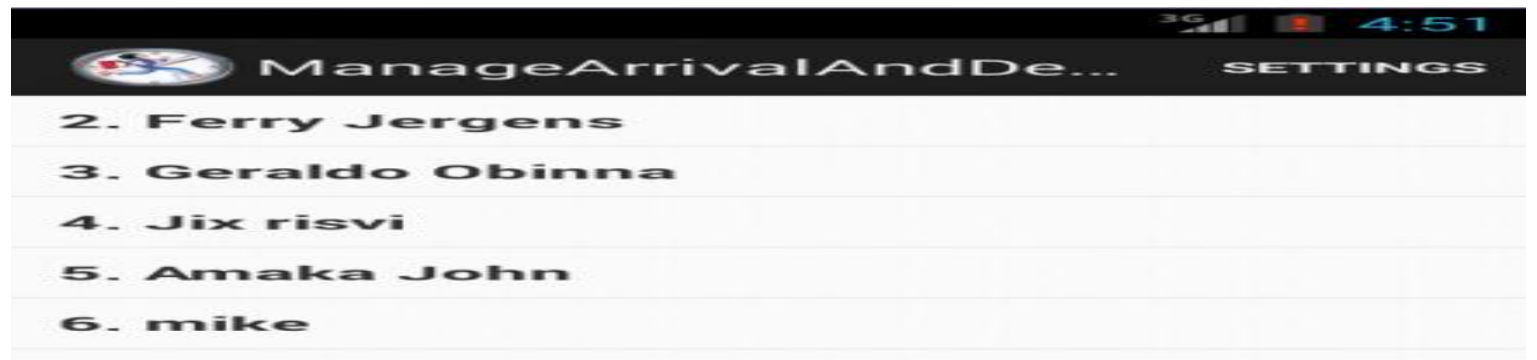

Figure 6: The Interface of the Existing Account

Figure 7 shows the interface display a successful sign in by an employer
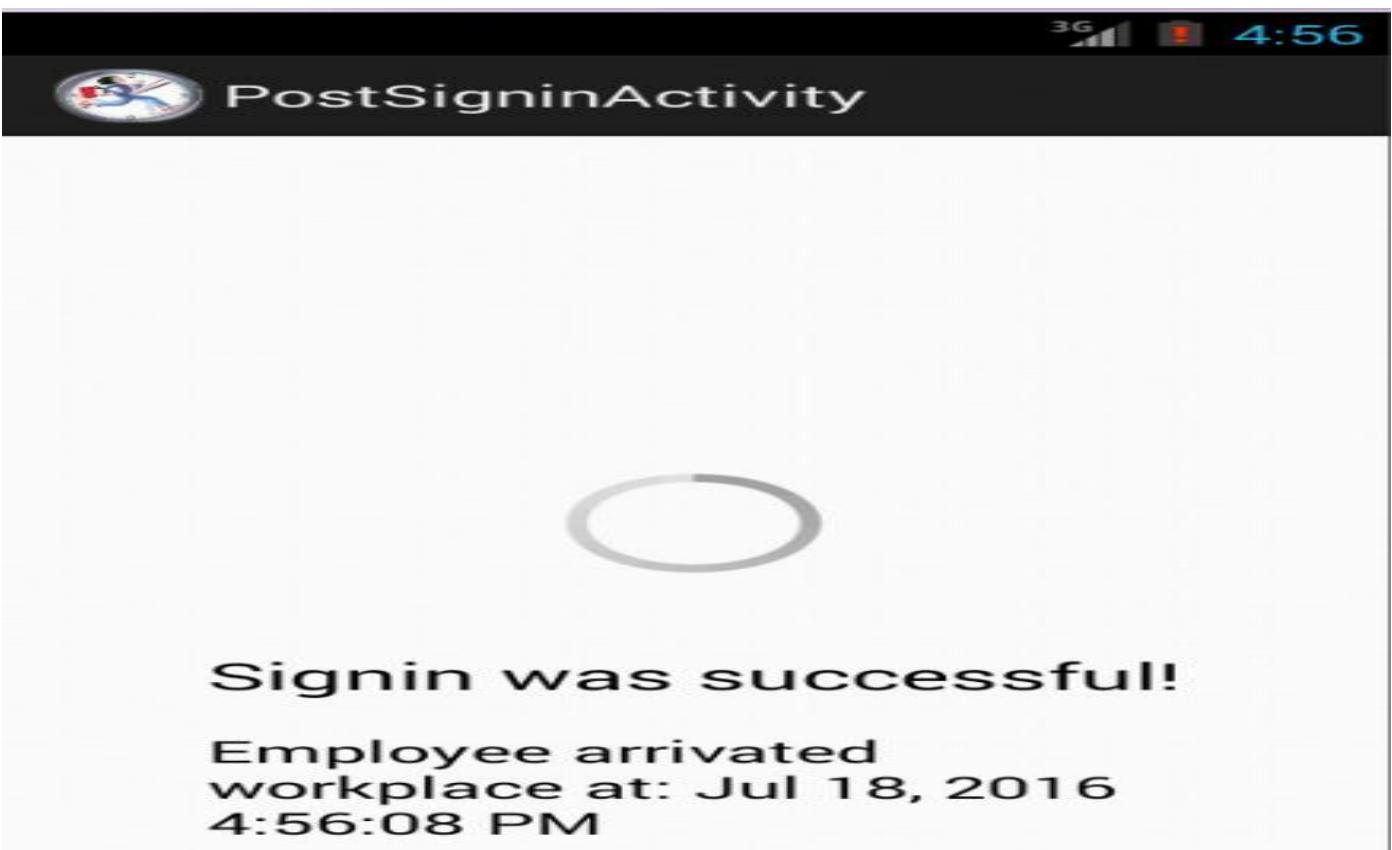

Figure 7: The Interface of the successful sign in by an employer

\section{CONCLUSION}

This application enables the managers to update the overall performance of the employees in their respective areas. This monitoring system is a revolutionary mobile application which uses Android OS for monitoring time attendance of employees. There is no need of manual entering of the daily activity details of each employee onto the database. It completely abolishes the traditional way of calculating performances. This will considerably reduce the paperwork and save ones precious time. This application makes good use of the recent mobile development technologies and thereby increases the overall performance of the employees, also has a substantial business value because it reduces hardware and maintenance cost and increases customer's satisfaction.

\section{REFERENCES}

[1] Sonal Kasliwal, Sushma Kotkar and H.D.Gadade (2016),Employee Tracking and Monitoring System Using Android International Journal of Innovative Research in Advanced Engineering (IJIRAE) SSN: 23492763, Issue 03, Volume 3, page 1-4

[2] Priti P. Dafale, Nilima N. Mandal and Divyamala B. Thakare (2015), monitoring employee's smartphone using android application, Proceedings of 20th IRF International Conference, Chennai, India, ISBN: 978-9384209-01-8

[3] Aparna Chandran (2013), Smartphone Monitoring System, International Journal of Computer Science \& Engineering Technology (IJCSET) ISSN : 2229-3345 Vol. 4 No. 04, page 451-452 
[4] Shermin Sultana1, Asma Enayet1 and Ishrat Jahan Mouri (2015), A Smart, Location Based Time And Attendance Tracking System Using Android Application International Journal Of Computer Science, Engineering And Information Technology (Ijcseit), Vol. 5,No.1,

[5] M.D. Nirmal, Rohit Koul, Halne Atul, Gagare Tejaswita and Kharde Mayura (2016), Employee Surveillance System Using Android Smart Phone, IJARIIE-ISSN $(O)$ 2395-4396, Vol-2 Issue-2

[6] Ashwini Jaybhaye, Prajakta Kokare, Bhakti Toradmal and Tanmay Kulkarni (2015), Employee Monitoring System Using Android Smartphone, International Engineering Research Journal (IERJ) Volume 1 Issue 2 Page 32-35, ISSN 2395-1621

[7] Kalyani Bhagwat Priyanka Salunkhe and Shamal Bangar. (2015), Employee Monitoring System Using Android Smart Phone, International Journal on Recent and Innovation Trends in Computing and
Communication ISSN: 2321-8169 Volume: 3 Issue: 2 537 - 541537 IJRITCC.

[8] Shoewu, O, Makanjuola, N.T and Amisu, A.A, (2015) Design and Implementation of An Employee Monitoring System In Lasu Epe Campus, Lagos State University, Journal of Advancement in Engineering and Technology, Volume 4, Issue 1, ISSN: 2348-2931

[9] S.P. Avinaash Ram And J. Albert Mayan (2015), Mobile Attendance Management And Employee Registration Arpn Journal Of Engineering And Applied Sciences, Vol. 10, No. 8, Issn 1819-6608, page 37273730

[10] Nitin P. Jagtap, Kanchan A. Patil, Shaziya Sayyed Shakil and Nitin S. Ingle (2015), Mobile Activity Monitoring System Using Android Spy, International Journal of Advanced Research in Computer and Communication Engineering, Vol. 4, Issue 2, page 158-162 